\title{
Alternative Manoeuvres to Reduce Ship Scour
}

\begin{tabular}{|c|c|}
\hline Journal: & Journal of Navigation \\
\hline Manuscript ID & NAV-RA-2019-0210.R1 \\
\hline Manuscript Type: & Research Article \\
\hline $\begin{array}{r}\text { Date Submitted by the } \\
\text { Author: }\end{array}$ & $\mathrm{n} / \mathrm{a}$ \\
\hline Complete List of Authors: & $\begin{array}{l}\text { Castells-Sanabra, Marcella; Universitat Politècnica de Catalunya, } \\
\text { Engineering and Nautical Science } \\
\text { Mujal-Colilles, Anna; Universitat Politècnica de Catalunya, Engineering } \\
\text { and Nautical Science } \\
\text { Llull, Toni; Universitat Politècnica de Catalunya, Engineering and Nautical } \\
\text { Science } \\
\text { Moncunill, Jordi; Universitat Politècnica de Catalunya, Engineering and } \\
\text { Nautical Science } \\
\text { Grionella, Xavi; Universitat Politècnica de Catalunya, Civil and } \\
\text { Environmental Engineering } \\
\text { Martínez de Osés, Francisco Javier; Universitat Politècnica de Catalunya, } \\
\text { Nautical Sciences and engineering }\end{array}$ \\
\hline Keywords: & AIS, Manoeuvrability, Harbour, Propulsion, Ship Behaviour \\
\hline Abstract: & $\begin{array}{l}\text { Scouring and sedimentation effects on the seabed induced by ship } \\
\text { propellers during ship manoeuvring near harbour structures affect both } \\
\text { structure stability and ship manoeuvring capabilities. This contribution } \\
\text { proposes solutions at an operational level using the Automatic } \\
\text { Identification System (AIS) and a bridge simulator. Two new alternative } \\
\text { manoeuvres were designed and tested on a bridge simulator to obtain } \\
\text { expected maximum scour depth and their goodness was compared with } \\
\text { that of real manoeuvres i) using mooring lines, and ii) with tug } \\
\text { assistance. A total of } 42 \text { test scenarios combining several manoeuvres } \\
\text { and meteorological conditions were reproduced. Results confirmed a } \\
\text { clear reduction in erosion depth with the alternative manoeuvres, with } \\
\text { total reduction when using the tugboat. The presented methodology can } \\
\text { be very useful to Port Authorities to prevent the effects of ship erosion } \\
\text { on harbour infrastructures. }\end{array}$ \\
\hline
\end{tabular}

\section{SCHOLARONE Manuscripts}




\section{INTRODUCTION}

Vessel sizes have grown rapidly over recent years to enable the transportation of larger volumes of cargo and thus reduce freight rates. This increase has resulted in more powerful ships with greater manoeuvrability and capable of higher speeds and in time gains but using the same old quays designed to host ships with lower drafts and less powerful propulsion systems. These rapid changes in the maritime industry are causing unexpected problems to harbour authorities. Risks associated with these larger vessels should be evaluated to establish limits on vessel dimensions and manoeuvring capabilities and thus ensure safety, efficiency and environmentally responsible use of harbour infrastructures. One of these risks is how the scouring effect on the seabed induced by ship propellers during ship arrival and departure manoeuvres near the harbour structures can affect their stability: Bergh \& Magnussen, 1987; Chait, 1987; Fuehrer, Pohl, \& Römish, 1987; Hamill, Johnston, \& Stewart, 1999; Hamill, Ryan, \& Johnston, 2009 studied the propeller scouring effects using experimental scenarios; MujalColilles et al., 2017a compared and applied previous formulas to a real case. Latelly, Schokking, Janssen, \& Verhagen, 2003; Symonds, Britton, Donald, \& Loehr, 2017; Tan \& Yüksel, 2018 were using both numerical and experimental methods to predict propeller scouring effects. When scour occurs, the eroded material is deposited in other areas of the harbour, affecting ship manoeuvring capabilities due to a significant reduction of the water column height. Moreover, in areas of the harbour basin where the seafloor may be polluted, erosion and further resuspension of bed material can cause an important environmental problem. PIANC guidelines (2015) propose several methods to estimate propeller effects.

So far the scouring problem has been handled by harbour authorities by trying to find a structural solution and omitting existing operational solutions. However, manoeuvre patterns play an important role and, therefore, the scouring action may also be analysed from this point of view. Thus, knowledge of vessel tracks obtained through Automatic Identification System (AIS) data is useful to obtain daily manoeuvre patterns, traffic densities, transit duration performance and other decision support frameworks (Aarsæther \& Moan, 2009; Pallotta et al., 2013; Silveira, Teixeira, \& Soares, 2013; Greidanus, Alvarez, Eriksen, \& Gammieri, 2016; Castells-Sanabra et al., 2017). Manoeuvre patterns obtained from AIS data can be further reproduced using a real-time full mission bridge simulator regardless of cost and time (Llull et al., 2020). Simulator studies offer accuracy and provide important information of the real 
manoeuvre (Aarsæther and Moan, 2007). Additionally, the bridge simulator can be used to increase the number of the manoeuvring scenarios in different weather conditions.

In this work, we use real AIS data to analyse and further reproduce the manoeuvres that are causing or have caused an important scouring problem in harbour basins and structures. We focus on a case study but this is a general problem that other harbours are facing and will face in the near future. We use a bridge simulator to propose new manoeuvres which minimise scour and avoid costly infrastructural solutions.

\section{CASE STUDY}

The study quay is located at the North-West Mediterranean Sea. The exact location will be kept confidential due to Port Authority requirements. The ship considered is a Ro-Ro ship type with a daily docking frequency at a quay with a total depth between 10 and 12 metres. The ship particulars are typical values for Ro-Ro ships, with its dimensions being 199 metres of length and 26 metres of beam. The ship is fitted with two main engines developing $12775 \mathrm{~kW}$ each, two controllable pitch propellers (CPP) and two bow thrusters.

A plan view of the berthing structure and a bathymetric survey of the study area are shown in Figure 1. The berthing structure consists of a Ro-Ro berth, orientated NE, and the ship moored starboard side. The hole scoured by the main propellers of a ferry-type vessel with daily docking frequency (Llull et al., 2020) reached a total depth of 17.5 mbsl (metres below sea level), about 5-7 metres deeper than the original quay seafloor. According to Mujal-Colilles et al. (2017b), a ferry-type vessel with a daily docking frequency can reach an eroding rate of up to 1.2 metres in 3 months. The seafloor is composed of a first layer of $0.5 \mathrm{~m}$ in thickness and muddy and sandy sediment lying on a gravel layer of $d_{50}=2 \mathrm{~mm}$ (2015 data provided by the Port Authority). 


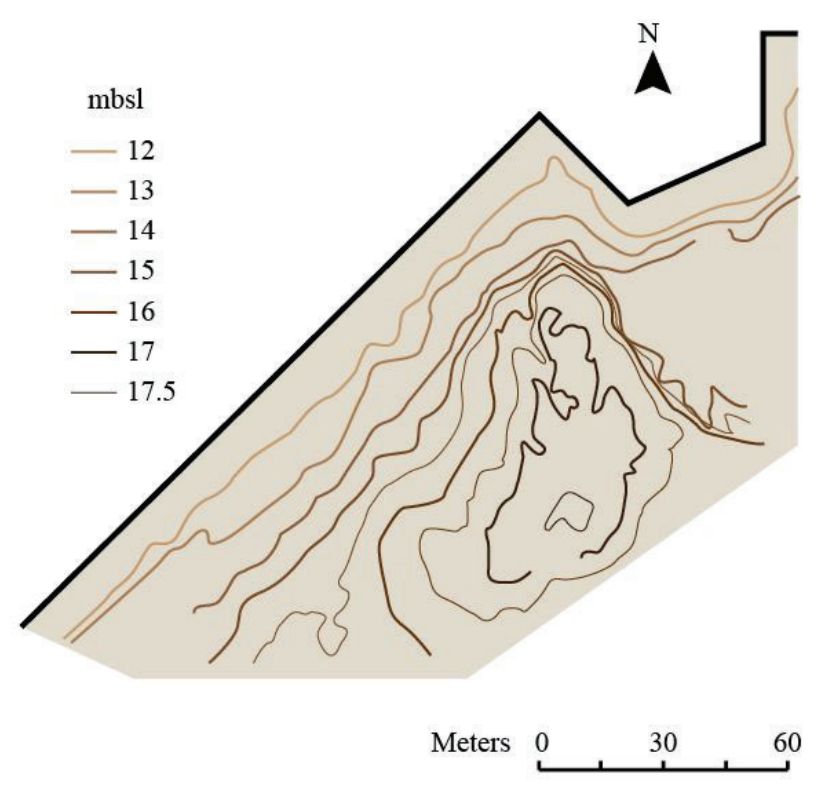

Figure 1. Bathymetry of the area of interest. Colour scale represents metres below sea level (mbsl)

Literature review on safety of ship berthing operations has indicated that weather and geography are common factors leading to shipping accidents (Hsu, 2015). The specific meteorological conditions of the port, based on average monthly wind data, are analysed from historical data of the Spanish Meteorological Agency (AEMET). The effect of the wind on a berthing ship can be significant. It varies with wind intensity and relative direction (onshore or offshore) and ship speed and course. For instance, in strong winds it can be difficult to counteract this effect without tug assistance or the use of bow thrusters. Figure 2 shows that the prevailing wind speed is force 2 in the Beaufort wind scale, the percentage of calm weather is around $24 \%$ (forces 0 and 1 ) and the percentage above force 5 in the Beaufort wind scale is less than 5\%. The prevailing wind direction is NE (around 14\%) and critical meteorological conditions in the area are NW and SW winds. Historical data show that NW events are less frequent but more intense than SW events.
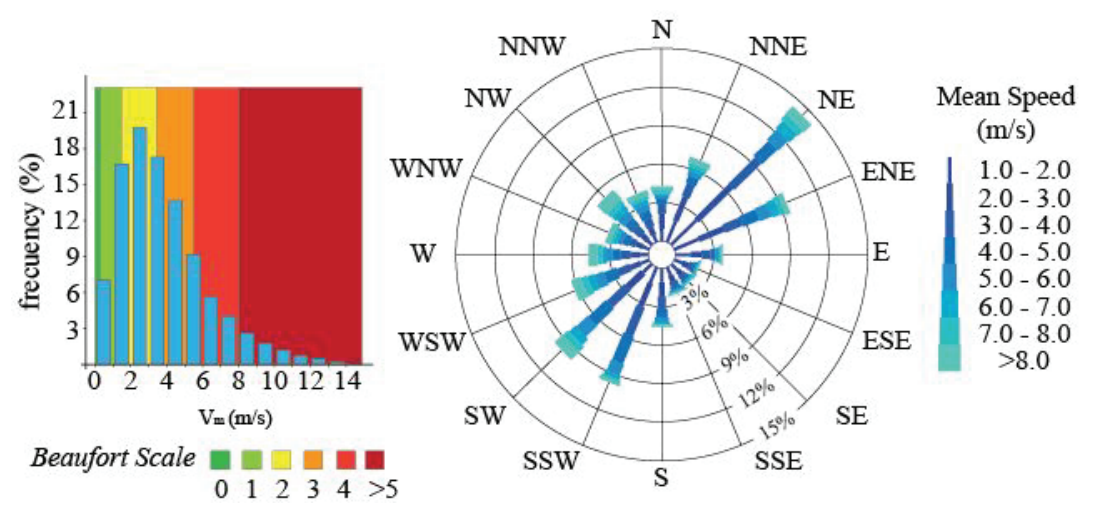

Figure 2. Mean wind speed histogram (left) in Beaufort Scale (Bf) and wind speed \& direction rose plot (right) at the study port. 2012-2018 (Spanish Meteorological Agency) 
Considering the NE-SW orientation of the study quay, the most harmful wind directions are, hypothetically, perpendicular and parallel to it, i.e. SE and SW winds for departure manoeuvers and NW and SW winds for arrival manoeuvers. However, as according to Figure 2, NE winds are the prevailing wind direction, they will be considered in this study, whereas SE winds will be disregarded because their small prevalence has a lower impact on departure manoeuvers. Wind intensities used will be calm, $\mathrm{Bf}=2$ and $\mathrm{Bf}=4$, since calm and $\mathrm{Bf}=2$ are the most frequent ones and $\mathrm{Bf}=4$ is the highest wind force $(\mathrm{Bf}=5$ will not be considered because it is less frequent).

\section{METHODS}

The methodology to study alternative manoeuvres that minimise scouring effects combines different individual methods, as detailed in Figure 3. First, AIS reports of a real Ro-Ro ship are used to study ship manoeuvre patterns and their statistical representability. Representative arrival and departure manoeuvres at the selected harbour area are reproduced with the real-time full mission bridge simulator Transas NTPro 5000-v-5.35 and using previous AIS data to obtain scouring related propeller variables and calibrate the method with the scouring effects on the harbour basin. Thereafter, new alternative manoeuvres are designed and tested on the bridge simulator to obtain, again, expected maximum scour depth and compare their goodness.

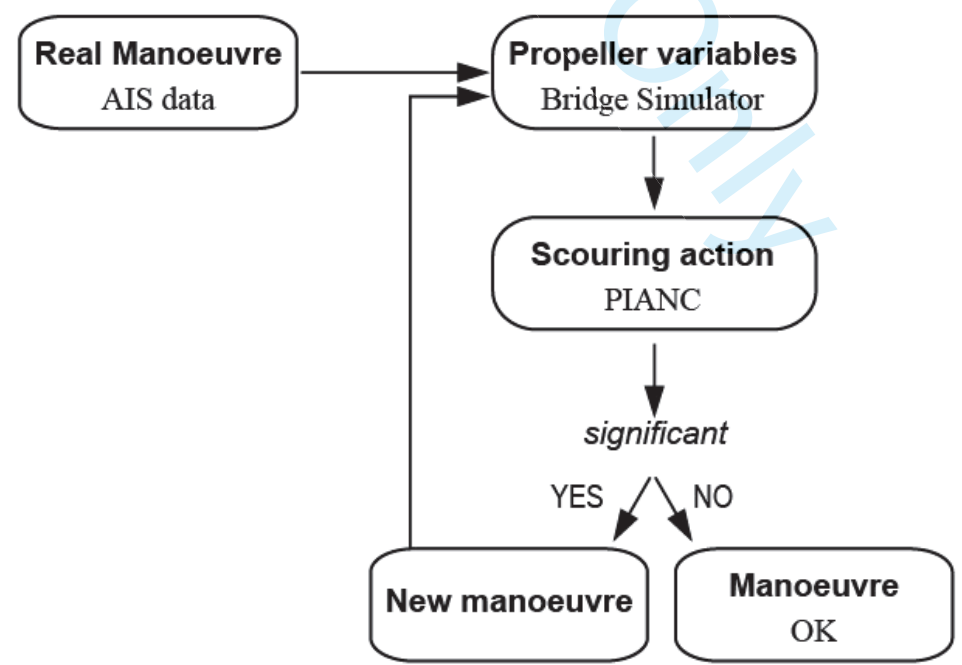

Figure 3. Combined methodology scheme

\subsection{Manoeuvring pattern from AIS Data}

AIS is an automated, autonomous tracking system for ship identification and location acting as a transponder and operating in the VHF maritime band. It is a valuable source of static and 
dynamic ship information and an analysis tool of harbour and open sea manoeuvres. AIS data reports were obtained from a Marine Traffic website (marinetraffic.com) from August $1^{\text {st }}$ to November $30^{\text {th }}, 2018$. To identify and reproduce manoeuvre patterns, 115 (58 departure and 57 arrival) manoeuvres were analysed and the following data of each manoeuvre were extracted: Coordinated Universal Time (UTC), position (latitude and longitude), Speed Over Ground (SOG) and Course Over Ground (COG). Marine Traffic collects, decodes and presents these data in near real-time depiction with a frequency on a 60 -second basis. The position to stop/start recording AIS data was (i) for departure manoeuvres, when the ship departs the port near the harbour mouth and reaches a speed of 7 knots, and (ii) for arrival manoeuvres, once the ship has passed through the harbour mouth and speeds down to less than 7 knots.

Although AIS data revealed similar kinematics, there could be differences between real manoeuvres performed by different pilots/masters in terms of engine orders. Manoeuvres reproduced on the bridge simulator are always very smooth, in the sense that aggressive changes in telegraph orders are avoided. However, these aggressive changes represent a temporary, insignificant impact and will probably not affect final scour results.

\subsection{Full Mission Bridge Simulator Test}

The study ship used in the bridge simulator was chosen to be closer to the real study ship, both in terms of ship particulars and propulsion system. Table 1 shows the particulars of the study ship and the simulator ship used in this research. The main differences lie in the length and engine power, with the real study ship being slightly larger. However, these differences do not affect the results substantially, as shown in (Llull et al., 2018) since the propeller characteristics are similar.

Table 1. Study Ro-Ro ship and simulator ship particulars

\begin{tabular}{|l|l|l|}
\hline Parameter & Study ship & Simulator ship \\
\hline Length & $199 \mathrm{~m}$ & $182 \mathrm{~m}$ \\
\hline Draft & $6.4 \mathrm{~m}$ & $6.5 \mathrm{~m}$ \\
\hline Beam & $26 \mathrm{~m}$ & $25.5 \mathrm{~m}$ \\
\hline Propulsion & $12775 \mathrm{~kW}$ & $11520 \mathrm{~kW}$ \\
\hline Propellers & $2 \mathrm{CPP}$ & $2 \mathrm{CPP}$ \\
\hline Propeller diameter $\left(D_{p}\right)$ & $5.1 \mathrm{~m}$ & $5 \mathrm{~m}$ \\
\hline Propeller rotating speed $(\mathrm{n})$ & $137 \mathrm{rpm}$ & $137 \mathrm{rpm}$ \\
\hline
\end{tabular}


A total of 42 different tests were performed by combining the following variables: manoeuvre scenario (arrival and departure), type of manoeuvre (real and alternative) and meteorological conditions, as detailed in Table 2.

Table 2. Test description. Each test contains three different wind intensities (calm, $2 B f$ and $4 B f$ (Bf, Beaufort wind force scale)) and three different wind directions (NW, NE and $S W)$.

\begin{tabular}{|c|c|c|c|}
\hline Type of test & Scenario & Wind Intensity & Wind direction \\
\hline \multirow{4}{*}{ Real manoeuvre case (RC) } & \multirow[b]{2}{*}{ Arrival } & Calm & - \\
\hline & & $2 \mathrm{Bf}$ and $4 \mathrm{Bf}$ & $\mathrm{NW}, \mathrm{NE}$ and $\mathrm{SW}$ \\
\hline & \multirow[b]{2}{*}{ Departure } & Calm & - \\
\hline & & $2 \mathrm{Bf}$ and $4 \mathrm{Bf}$ & NW, NE and SW \\
\hline \multirow{4}{*}{$\begin{array}{l}\text { Alternative manoeuvre } 1 \\
\text { without tug assistance (A1) }\end{array}$} & \multirow[b]{2}{*}{ Arrival } & Calm & - \\
\hline & & $2 \mathrm{Bf}$ and $4 \mathrm{Bf}$ & $\mathrm{NW}, \mathrm{NE}$ and $\mathrm{SW}$ \\
\hline & \multirow[b]{2}{*}{ Departure } & Calm & - \\
\hline & & $2 \mathrm{Bf}$ and $4 \mathrm{Bf}$ & $\mathrm{NW}, \mathrm{NE}$ and SW \\
\hline \multirow{4}{*}{$\begin{array}{l}\text { Alternative manoeuvre } 2 \text { with } \\
\text { tug assistance (A2) }\end{array}$} & \multirow[b]{2}{*}{ Arrival } & Calm & - \\
\hline & & $2 \mathrm{Bf}$ and $4 \mathrm{Bf}$ & $\mathrm{NW}, \mathrm{NE}$ and $\mathrm{SW}$ \\
\hline & \multirow[b]{2}{*}{ Departure } & Calm & - \\
\hline & & $2 \mathrm{Bf}$ and $4 \mathrm{Bf}$ & $\mathrm{NW}, \mathrm{NE}$ and $\mathrm{SW}$ \\
\hline
\end{tabular}

Alternative manoeuvres were proposed after studying the real manoeuvres and informal surveys conducted among local experienced pilots. The requirements of these alternative manoeuvres were (i) reduce or maintain the power of main stern propellers, and (ii) reduce or maintain the duration of the manoeuvres considering the weather conditions described in Table 2. Two alternative manoeuvres were proposed: (A1) without tug assistance and using mooring lines (for departure) and starting the turning circle manoeuvre before (for arrival), and (A2) with tug assistance and without using main propulsion. This second alternative manoeuvre was considered because larger ships will often require tug assistance (Hawkswood, Lafeber and Hawkswood, 2014) and the bridge simulator used has the option to add a tug with a secondary bridge.

\subsection{Scouring estimation}

The propeller parameters obtained on the full mission bridge simulator were used to calculate one of the most important parameters to obtain the scouring potential, i.e. efflux velocity $\left(\mathrm{V}_{0}\right)$, 
by a widely used formulation. (Blaauw and van de Kaa, 1978) proposed an expression based on experimental tests on scouring effects which fixes the minimum Reynolds number of the propeller and jet flow to avoid scaling effects:

$$
V_{0}=1.48\left(\frac{P}{\rho_{w} D_{p}^{2}}\right)^{\frac{1}{3}}
$$

where $P=$ engine power $(\mathrm{W}) ; \rho_{w}=$ density of the water $\left(\mathrm{kg} \cdot \mathrm{m}^{-3)}\right.$ and $D_{p}=$ diameter of the main propeller (m). See Figure 4.

The scouring action of the propeller was computed in front of a closed quay wall for noncohesive material (Römisch and Hering, 2002) using the expression proposed by PIANC (2015):

$$
\begin{array}{ll}
1^{\text {st }} \text { phase } & \frac{\varepsilon_{\max }}{d_{85}}=0.1 C_{m}\left(\frac{B}{B_{c r}}\right)^{13} \text { when: } 1 \leq \frac{B}{B_{c r}} \leq 1.4 \\
2^{\text {nd }} \text { phase } & \frac{\varepsilon_{\max }}{d_{85}}=4.6 C_{m}\left(\frac{B}{B_{c r}}\right)^{2.25} \text { when: } \frac{B}{B_{c r}} \geq 1.4
\end{array}
$$

where $\varepsilon_{\max }=$ final (or equilibrium) scour depth (m); $B_{c r}=$ critical stability coefficient of bed material, $\sim 1.2 ; C_{m}=0.3$ during berthing manoeuvres; $d_{85}=$ diameter of bed material, $85 \%$ passing median stone diameter and $B=$ stability coefficient. Considering that the diameter of the bed material available is $d_{50}$ and after a sensitivity analysis showing that this variable is not key in the results, we used $d_{50}$.

$$
\begin{gathered}
B=\frac{V_{s b}}{\sqrt{d_{85} g\left(\frac{\rho_{s-\rho_{w}}}{\rho_{w}}-1\right)}} \\
\frac{V_{s b}}{V_{0}}=1.9 \alpha_{L}\left(\frac{D_{p}}{L}\right)
\end{gathered}
$$

where $V_{s b}=$ flow velocity near the bed $(\mathrm{m} \cdot \mathrm{s}) ; g=$ gravity constant $\left(\mathrm{m} \cdot \mathrm{s}^{-2}\right) ; \rho_{s}=$ density of sediment $\left(\mathrm{kg} \cdot \mathrm{m}^{-3}\right) ; \rho_{w}=$ density of water $\left(\mathrm{kg} \cdot \mathrm{m}^{-3}\right) ; \alpha_{L}=$ coefficient related to distance between propeller and seabed, $\alpha_{L}=1$ and $L=$ distance between ship and quay wall (m), see Figure 4. 


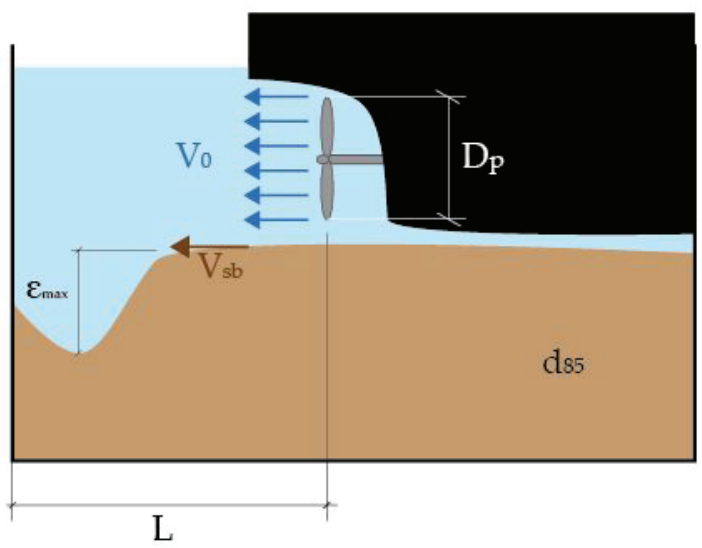

Figure 4. Sketch of the variables in Eq. (1) to Eq. (5)

\section{RESULTS}

\subsection{AIS Data}

The daily manoeuvres of the study ship were analysed to identify the manoeuvre patterns over the area of interest. Figure 5 plots the arrival and departure lat-long location and Speed Over Ground of the AIS system.
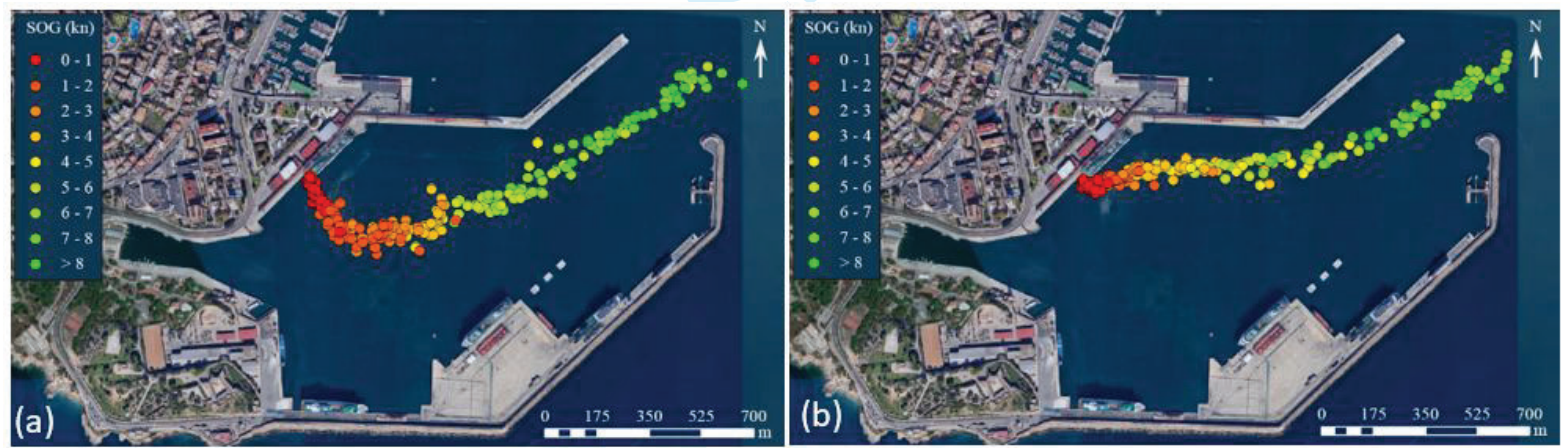

Figure 5. Ship position and Speed Over Ground (SOG) from AIS data at case study quay from August 1, 2018 to November 30, 2018. (a) Departure manoeuvres;(b) Arrival manoeuvres

The departure manoeuvre, Figure 5a, consists of lateral displacement with the starboard propeller running astern and the port propeller running ahead at low regime during the first minutes. Ship speed is 0.5 knots and the bow thruster is used intermittently to maintain a constant heading and thus compensate for torque. After 10 minutes, the propellers reverse and the ship turns to port from a heading of $225^{\circ}$ to $65^{\circ}$ approximately and with speed increasing from 2 to 5 knots. Finally, both propellers run parallel ahead and the ship departs the port. The approximate total duration of the departure manoeuvre is 18 minutes.

The arrival manoeuvre at the harbour basin area, Figure 5b, starts with the ship turning to starboard to a heading of about $270^{\circ}$ and speed reducing from 7 to 5 knots during the first three minutes. Then the ship turns to port until parallel to the quay wall, i.e. a heading of $230^{\circ}$, with 
both stern propellers working astern but with the port propeller regime being higher than the starboard propeller one. Now speed is below 1 knot. To begin the lateral movement towards the quayside, the starboard propeller is changed ahead while the port propeller is astern, generating a torque. The bow thruster is used during the final approach to compensate for this torque. Inertia drives the ship to the quayside. The approximate total duration of the arrival manoeuvre is 11 minutes.

Figure 6 plots the vessel heading and main propellers position of departure and arrival manoeuvres. As can be seen in Figure 6 (right), the position of main propellers coincides with the position of the maximum bathymetry in Figure 1 and shows that scour is entirely caused by the main stern propellers. This is likely due to the fact that they are bigger and have a lower clearance from the seafloor than the bow thrusters.

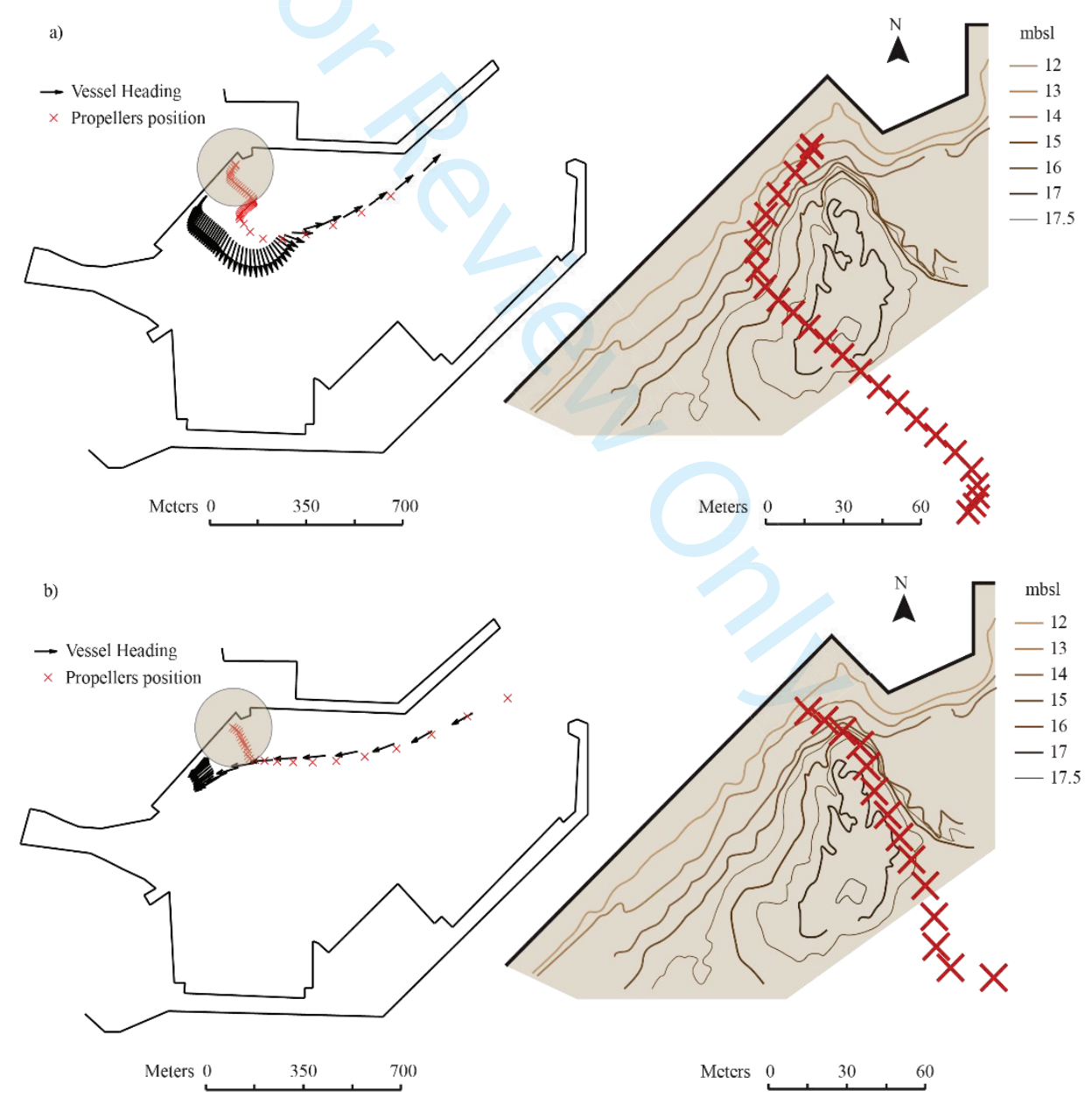

Figure 6. Ship heading and propellers position (left) and propeller position drawn on the bathymetry map (right) (a) Departure manoeuvres and (b) Arrival manoeuvres 


\subsection{Bridge simulator}

The above AIS data are necessary to mimic and reproduce the real manoeuvres on the bridge simulator. Bridge simulator results help to better understand manoeuvring and detect critical points related to scour caused by stern propellers. The real manoeuvres were simulated for the three weather scenarios in Table 2.
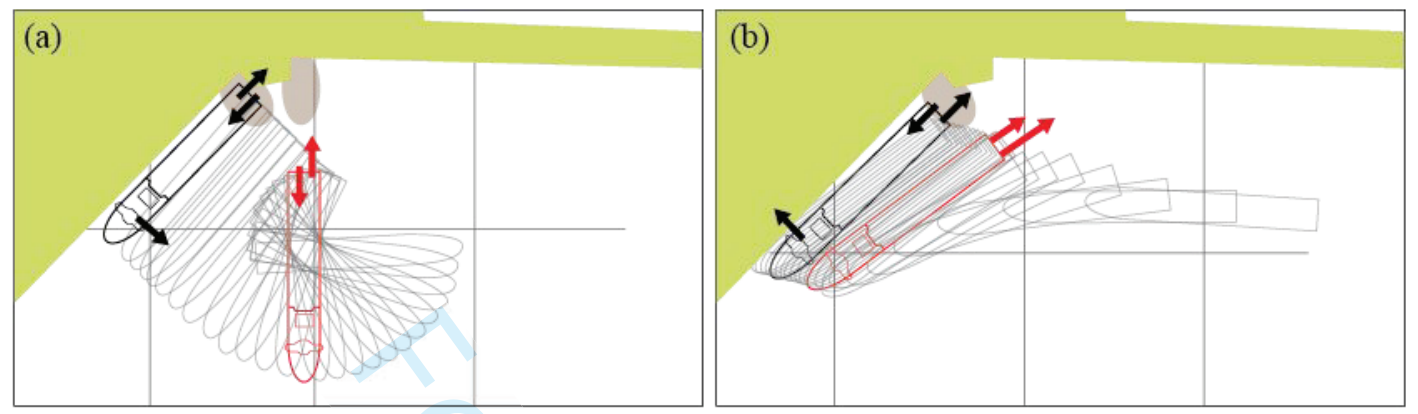

Figure 7. Bridge simulator scenarios (a) Departure manoeuvre and (b) Arrival manoeuvre. Black lines represent the closest ship position to the quay; red lines represent the ship manoeuvre departing or approaching the quay

Figure 7 shows the reproduction of the real manoeuvres on the bridge simulator in calm weather conditions.

The variable needed to estimate the scouring action during the manoeuvres is the engine power, $P$. However, we also used the propeller pitch ratio, $p$ ', and the main propeller rotation velocity, $n$, since they help to better understand the behaviour of manoeuvres. Figure 8 plots the evolution of these variables during the departure manoeuvre for two different weather conditions. 
(a)
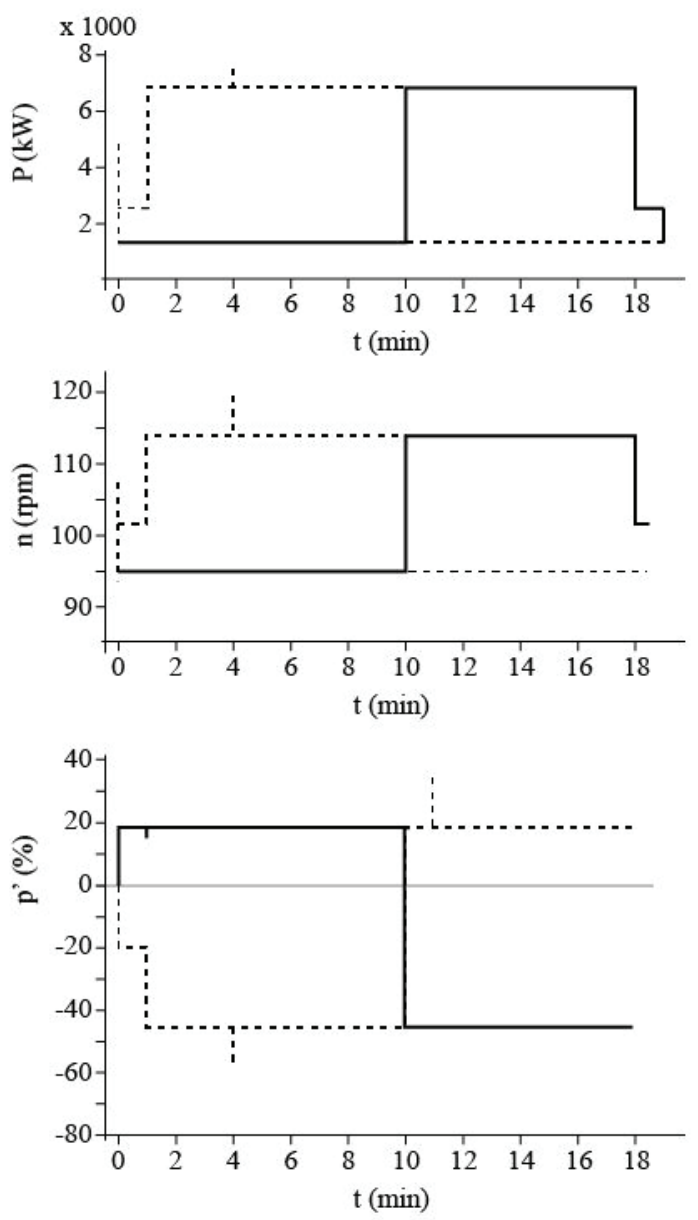

- port (b)
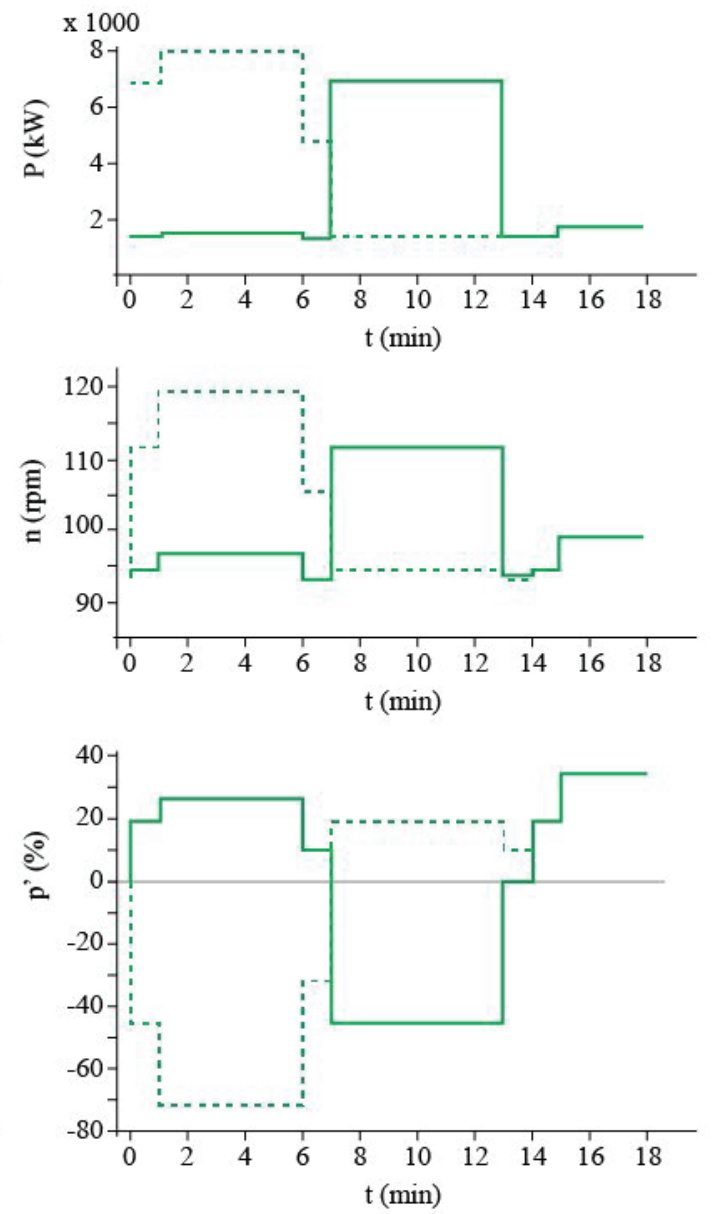

starboard

SW-2Bf

Figure 8. Time series of the propeller-related variables of the real departure manoeuvre reproduced on the bridge simulator in calm weather (black, left) and in Beaufort wind force $2 \mathrm{SW}$ wind direction weather (green, right). The rpm range is 90$130 \mathrm{rpm}$. Power (top); propeller rotation velocity (middle) and propeller pitch ratio (bottom)

The values of the propeller-related variables vary with weather conditions, with them being higher in worse weather conditions, see Figure 8. Using the results of Figure 8 as the input values in Eq. ( 1 ), we obtain the efflux velocity in Figure 9 as a relevant variable to predict scour depth. (Mujal-Colilles et al., 2018a; Tsinker, 1995) found that the scour depth of the seabed is greater when the propeller is working ahead and the greatest cavity depth occurs in the longitudinal axis of the ship. Since the main propellers of the study ship are variable pitch propellers, the operating regime of each propeller depends on the pitch sign: a) p'>0 the propeller is working ahead, and b) p' $<0$ the propeller is working astern. This is why only efflux velocity values during forward motion are taken into account in this research.

Although the 42 tests in Table 2 were reproduced and analysed on the bridge simulator, in this section we only present the potentially most harmful wind direction scenarios: (i) SW winds (calm, 2Bf and 4Bf) for departure manoeuvers since during the first minutes it is necessary to 
use the port propeller in ahead regime with more intensity, and (ii) NW winds (calm, 2Bf and 4Bf) for arrival manoeuvers since this wind direction is perpendicular to the quay and creates difficult approach conditions.
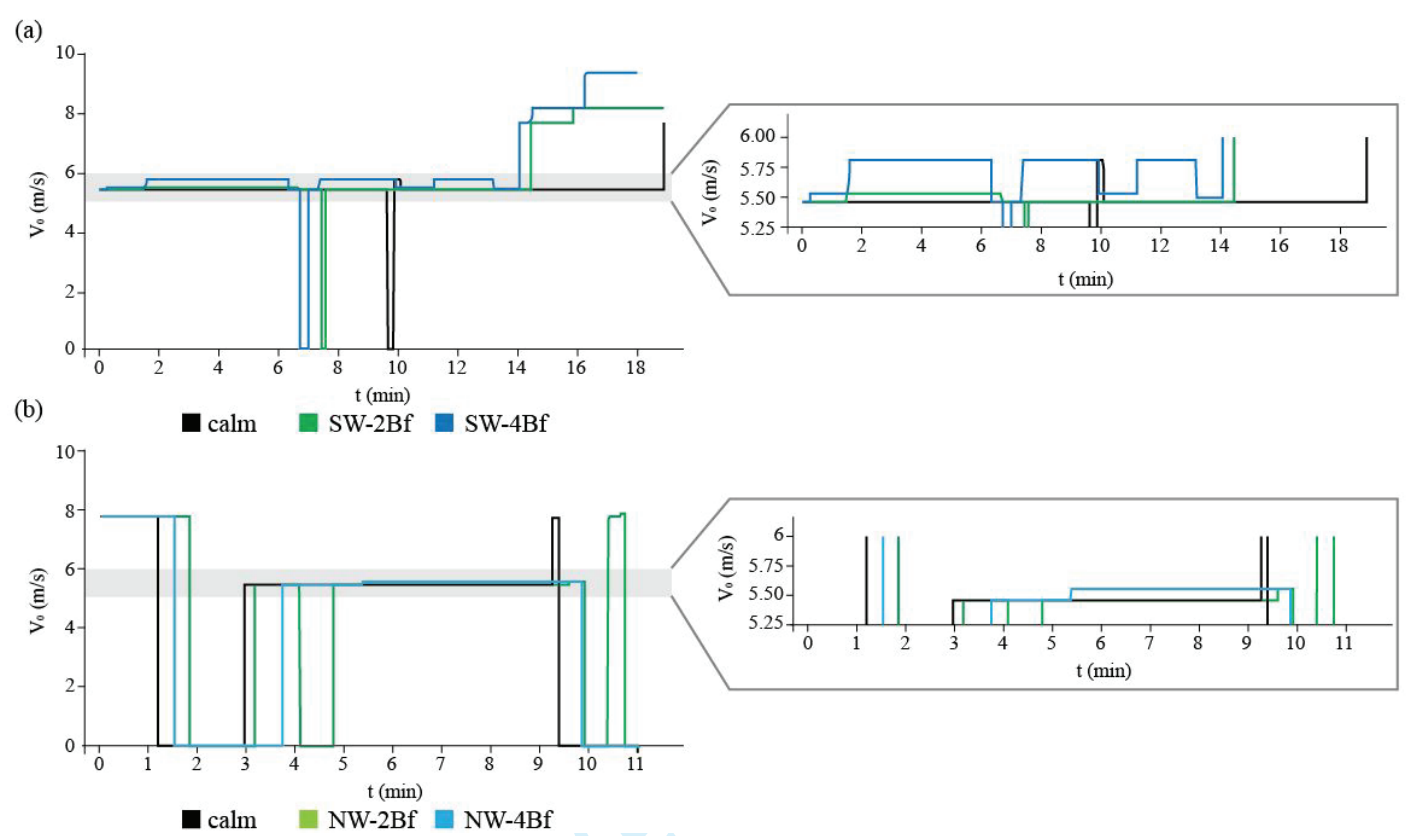

Figure 9. Efflux velocity $V_{0}$. (a) Real departure manoeuvre; (b) Real arrival manoeuvre. Calm (black), Beaufort wind force 2 (green) and Beaufort wind force 4 (blue)

Figure 9 shows efflux velocity values for the departure and arrival manoeuvres considering critical wind directions. Results are quite similar but show higher values for higher wind intensity in the real departure manoeuvre due to the difficulty of holding a ship on course in bad weather.

Efflux velocity values are used to obtain the expected scour depth from Eq. ( 2 - 5 ). Results for the real departure and arrival manoeuvres in the above weather conditions are shown in Figure 10. 
(a)

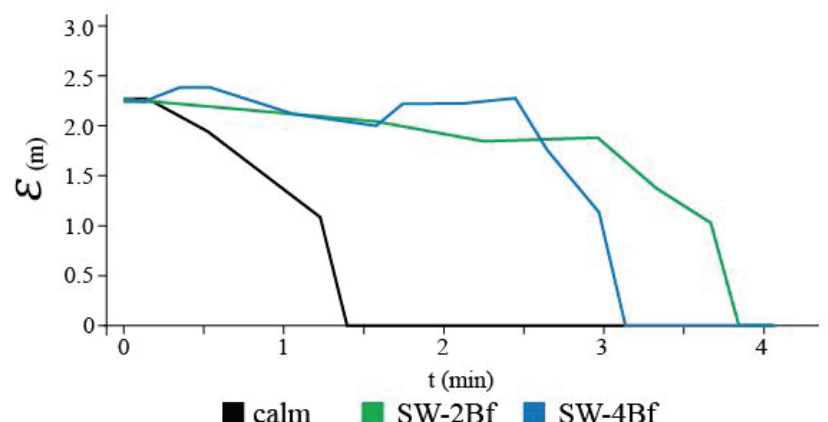

(b)

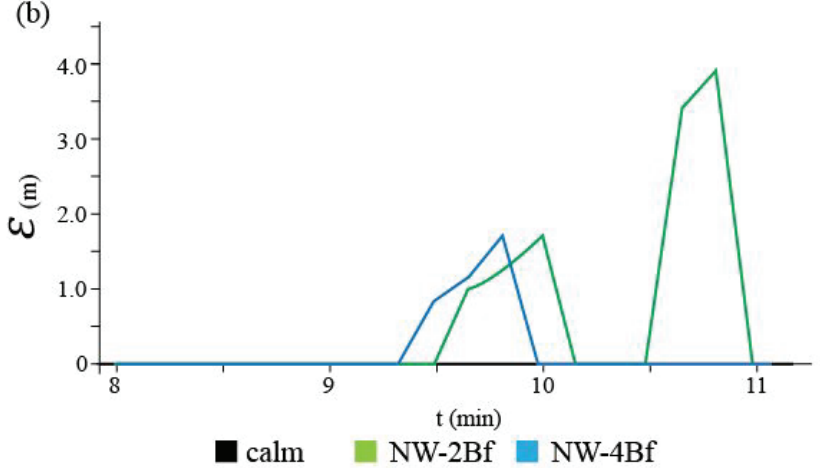

Figure 10. Potential erosion. (a) Real departure; (b) Real arrival. Calm (black), Beaufort wind force 2 (green) and Beaufort wind force 4 (blue)

Figure 10 shows the potential erosion for both manoeuvres considering critical wind direction. As can be observed, maximum scour only occurs at the beginning of the departure manoeuvre and at the end of the arrival manoeuvre due to the proximity of the dock wall.

\section{ALTERNATIVE MANOEUVRES}

After studying the real manoeuvres, alternative manoeuvres are analysed and proposed to minimise the scouring action of the main propellers. As described and documented in the sections above, the main variable responsible for scour is the use of stern propellers close to the dock wall. Therefore, scour can only be reduced by limiting the use of the main propulsion system at the beginning of the departure manoeuvre and at the end of the arrival manoeuvre using either mooring lines (specifically forward spring lines) or tug assistance.

First, alternative manoeuvres without tug assistance (A1) are suggested for both departure and arrival manoeuvres. During the first minutes of the alternative departure manoeuvre, the ship is going ahead on a forward spring line (see Figure 11). By going ahead on a forward spring line, the ship's bow is pulled into the harbour and the stern swings away from the dock. After the forward spring line is released, the ship moves parallel to the quay with the help of the bow thruster. Once the ship is safely clear from the berth, the swing movement starts. The alternative 
arrival manoeuvre is similar to the real manoeuvre but the turning circle to starboard starts before and so the manoeuvre takes longer.

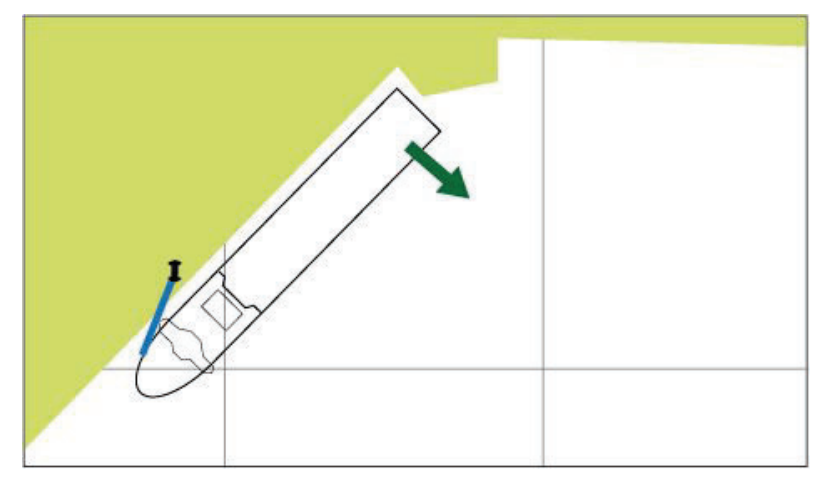

Figure 11. Alternative departure manoeuvre without tug assistance

Second, alternative manoeuvres with tug assistance (A2) are proposed. The transverse force is produced by using a tug (in the aft part) and the bow thruster (in the fore part) in both manoeuvres. In the departure manoeuvre, once the ship is safely clear from the berth, the swing movement starts (Figure 12a). The alternative arrival manoeuvre differs from the real manoeuvre in the final part. When the ship is just off the berth, a tug pushes the ship onto the berth from the aft port side with the help of the bow thruster (Figure 12b).
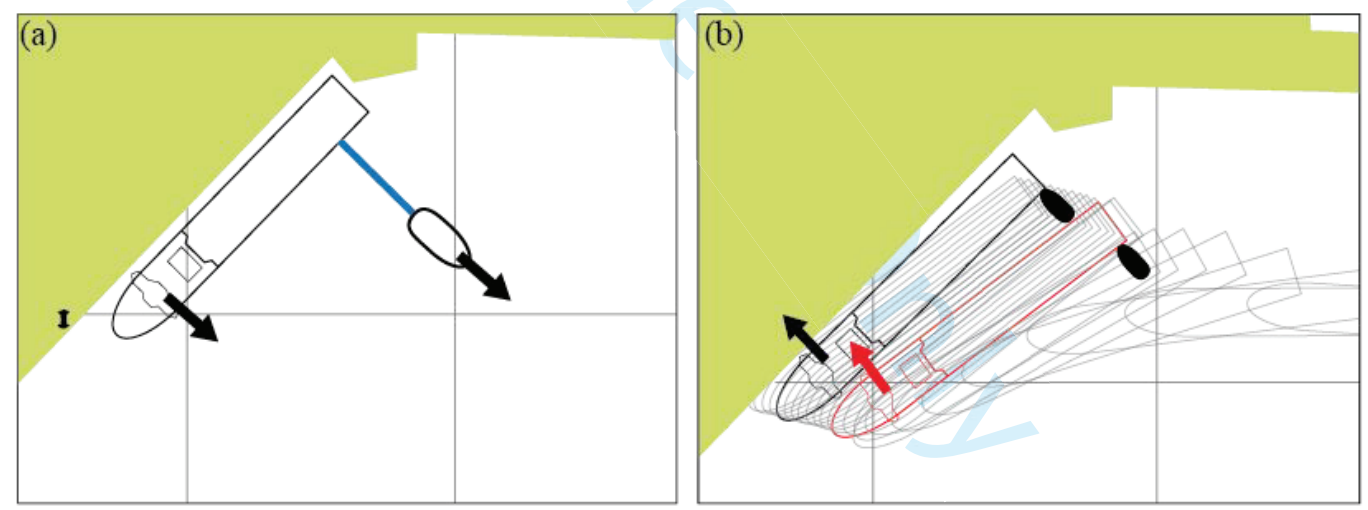

Figure 12. Alternative manoeuvres with tug assistance (a) Departure and (b) Arrival

Following the same methodology as in the previous section, Figure 13 plots the evolution of scour assuming a levelled seafloor. The scouring action of the real and alternative manoeuvres is compared, again, only for the potentially most critical wind directions (SW for departure and NW for arrival). 
(a)
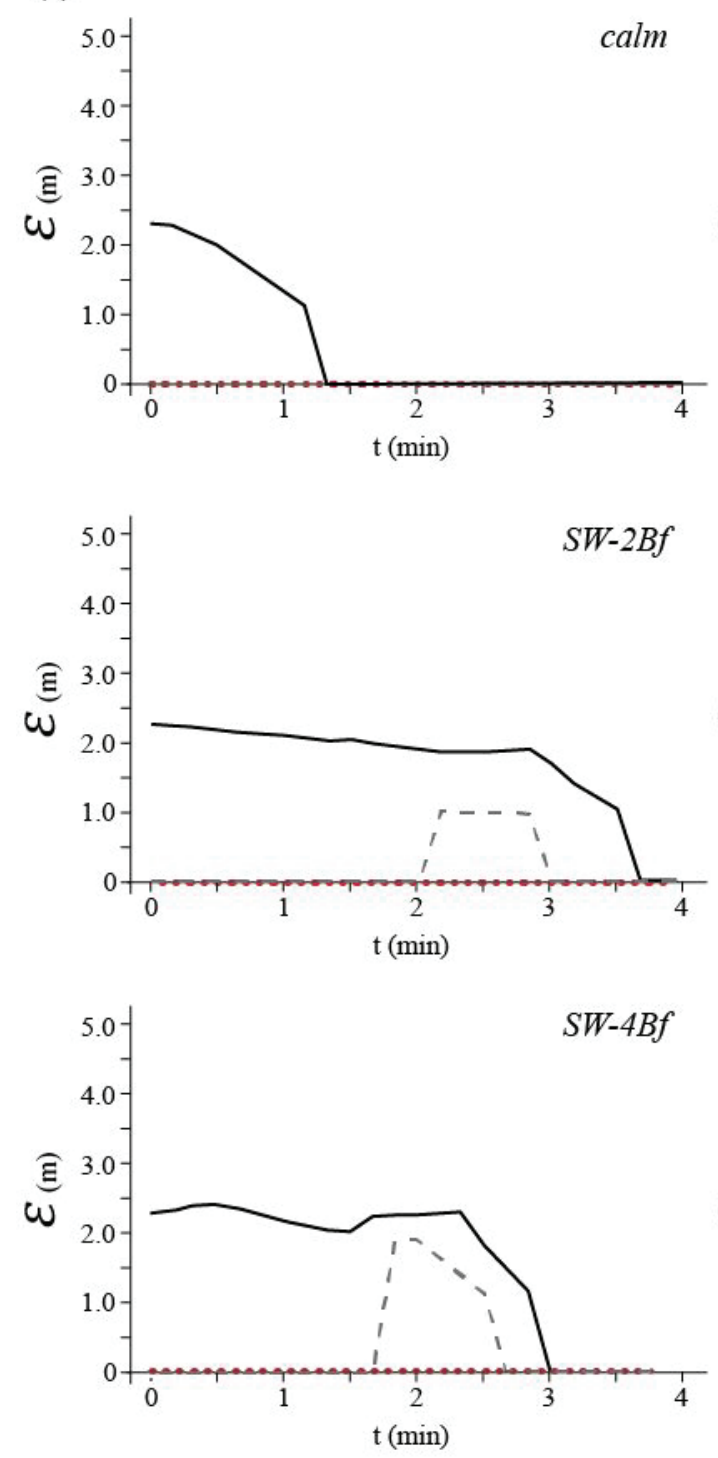

Real (b)
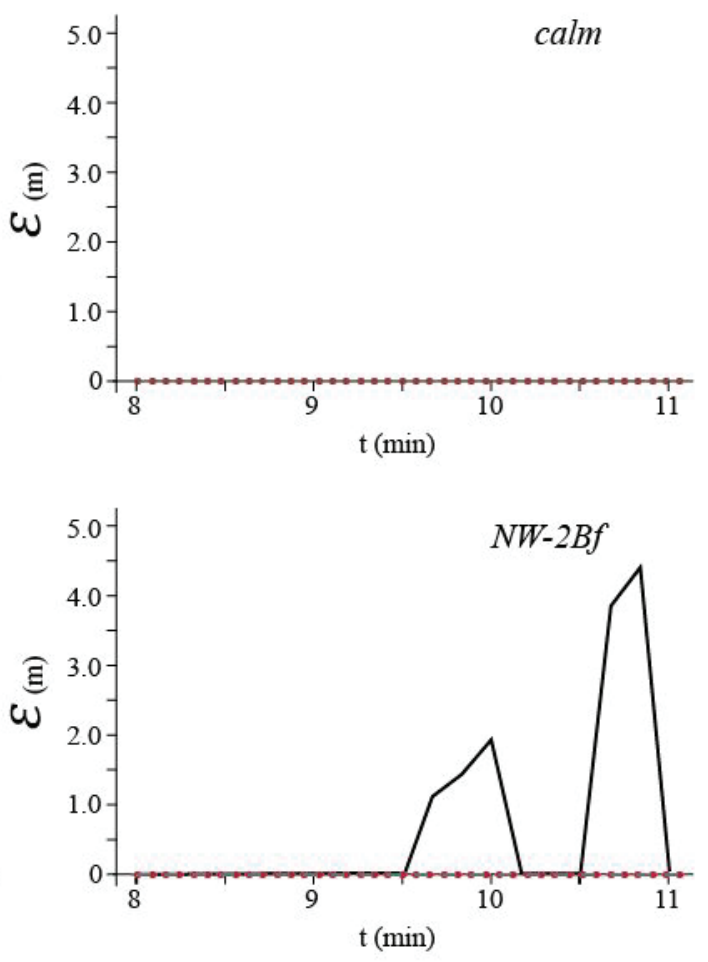

$N W-4 B f$

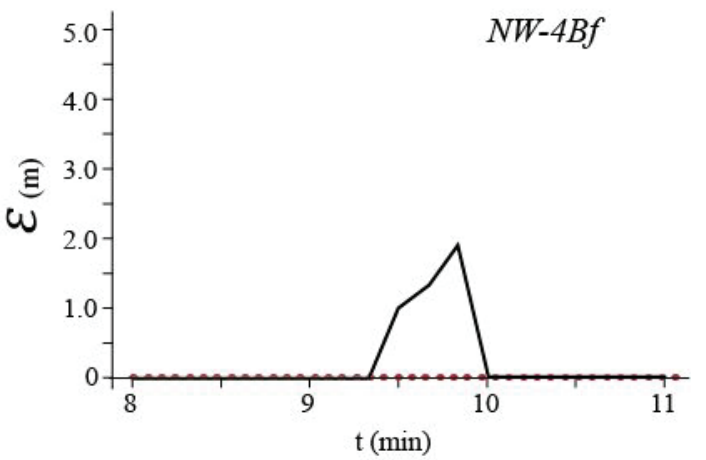

A2

Figure 13. Expected results of scour evolution during (a) departure manoeuvre and (b) arrival manoeuvre with the real manoeuvre -black continuous line-, alternative manoeuvre without tug assistance, A1, -grey dashed line- and alternative manoeuvre with tug assistance, A2, - red dotted line

Maximum scour results for all test cases combining all parameters in Table 2 and considering other wind directions (NE for departure and arrival, NW for departure and SW for arrival) are summarised in Figure 14.

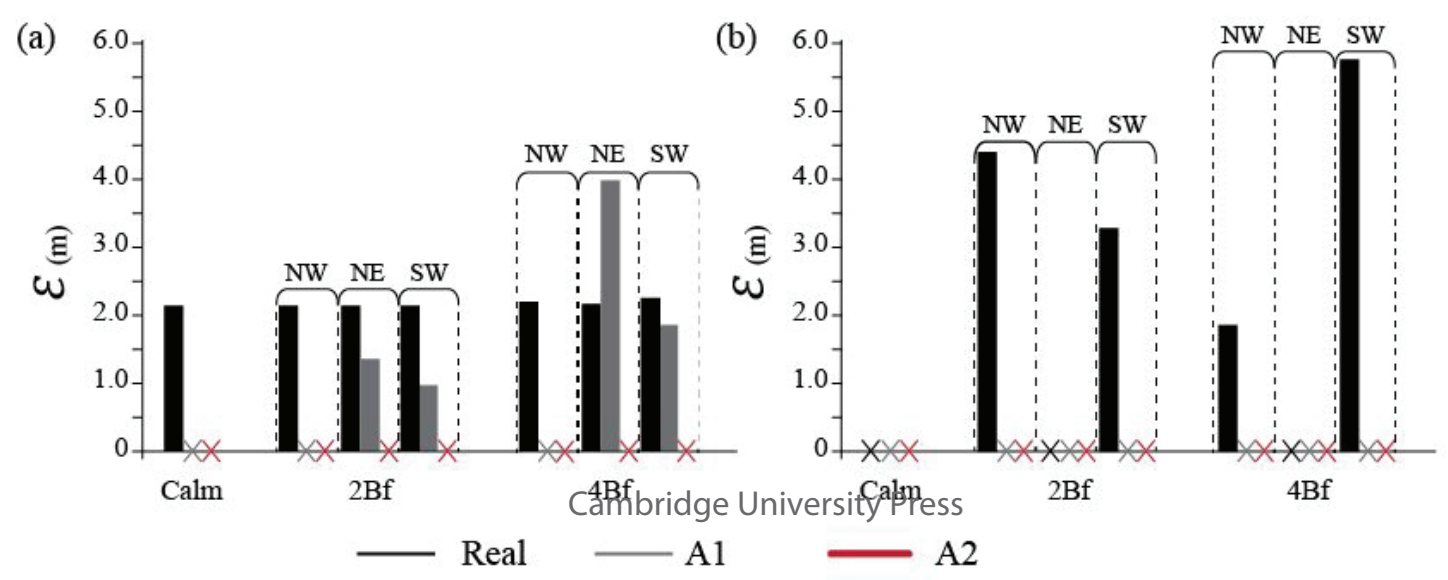


Figure 14. Maximum scour results for all test scenarios (a) Departure and (b) Arrival

As can be seen in Figure 13 and 14, scour caused by the main propellers is reduced or, in some cases, even eliminated when using the proposed alternative manoeuvres.

\section{DISCUSSION}

Preliminary results obtained in the above section were considered to analyse manoeuvre behaviour. The reproduction of manoeuvres on the real-time full mission bridge simulator made it possible to know (i) moment of the manoeuvre when scour caused by the main propellers is greatest, (ii) influence of wind direction and intensity on manoeuvres in terms of maximum erosion depth, and (iii) reduction in erosion obtained by using new manoeuvres.

An example of the parameters obtained from the bridge simulator for two different weather scenarios is given in Figure 8. In order to maintain ship manoeuvrability and hold the ship on course in wind conditions, power requirements are slightly higher in bad weather conditions and the manoeuvre is shorter because the propellers reverse after 7 minutes instead of 10 . During the first minutes of the manoeuvre, more power is required for the starboard propeller running astern, and the parameters of the port propeller running ahead are higher but quite similar to those of the calm weather manoeuvre. Thus, efflux velocity and erosion depth values in Figure 9a and 10a are slightly higher since only ahead motion (port propeller) is considered and weather conditions have a small influence on the final results. Figure 10 shows that maximum scour, $\varepsilon_{\max }$, occurs when the operating regime of the propeller is ahead (with the propeller wash in astern direction) and near the quay. Therefore, maximum scour occurs during the first three minutes of the departure manoeuvre (Figure 10a) and the last minutes of the arrival manoeuvre (Figure 10b).

Figure 13 shows how erosion depth is reduced with the two alternative manoeuvres. The alternative departure manoeuvres without tug assistance (Figure 13a) lead to a decrease in the power required by the port propeller during the first three minutes, resulting in total elimination of the scouring effects in calm weather, partial reduction in prevailing weather (2Bf) and slight reduction in adverse weather (4Bf). Scour depth is totally reduced when tug assistance is used. As for the arrival manoeuvres (Figure 13b), it is observed that erosion disappears at the end of the manoeuvres.

One of the requirements of the alternative manoeuvres was to maintain or reduce the power of main propellers. The alternative manoeuvres with tug assistance (A2) do not use main 
propulsion, leading to $100 \%$ reduction in power. Moreover, the main propulsion system of tugboats has a significantly smaller diameter and is located further from the seafloor, thus causing no erosion. As for the alternative manoeuvres without tug assistance (A1), the average maximum power reduction percentage is $6.5 \%$ for the departure manoeuvres. On the other hand, while the arrival manoeuvres do not result in maximum power reduction of main propellers, they take less time using this maximum power, leading to decreased scouring action. Another requirement was to reduce or at least not extend the duration of the manoeuvres. Tug assistance (A2) achieves an average time reduction of $26.4 \%$ in arrival and departure manoeuvres. Regarding the alternative manoeuvres without tug assistance (A1), the average time reduction is $29.5 \%$ for departure manoeuvres whereas most arrival manoeuvres take longer because the turning circle manoeuvre starts before.

Finally, Figure 14 shows all 42 test scenario results. As expected, the scouring action of real manoeuvres is always more severe than that of alternative ones for all weather scenarios, especially adverse weather conditions (4Bf). However, this contribution demonstrates that the hypothetically harmful wind directions in Figure 13 are not always the worst condition; the characteristics of each manoeuvre also play a crucial role in the occurrence of scour. Due to the relatively large distance between tug propellers and the seabed, and between the tug and the quay wall, Eq. ( 5 ), the alternative manoeuvres with tug assistance eliminate completely the scouring effect in all weather conditions. On the other hand, the alternative manoeuvres without tug assistance reduce erosion except for the arrival manoeuver in the worst weather (4Bf) and NE direction scenario. In this situation, the mooring line is subjected to large stresses and, when the ship is leaving the quay, it is necessary to increase the ahead regime of the port propeller to separate the ship from the quay. Weather conditions also affect the duration of manoeuvres. The alternative manoeuvers with tug assistance are always shorter than real ones, except in high wind conditions (4Bf). The alternative departure manoeuvers without tug assistance last approximately the same as real ones, but the arrival manoeuvers are slightly longer than real ones because the manoeuver starts before to reduce the power of stern propellers when the ship is approaching the quay.

(Mujal-Colilles et al., 2017b) found that maximum erosion occurs in the vicinity of the quay wall. Results of this study also confirm that scour is most likely to occur near the back quay in both manoeuvres and in all weather conditions, affecting dock infrastructures. Although Figure 14 shows higher values for arrival manoeuvres, the duration of their scouring action is shorter (less than 1 minute) compared with the departure manoeuvres (three minutes approximately), 
with the latter therefore posing the most damaging scenarios. These findings are in agreement with the experimental results of Mujal-Colilles et al. (2018b).

PIANC guidelines are used to calculate the maximum scour depth on the study quay. However, there is a lack of formulation to evaluate the potential scouring action of main propellers in a confined area. For this reason, (PIANC, 2015) proposes a set of equations extracted from (Römisch and Hering, 2002) to calculate scour caused by confined washes, but bearing in mind that their use is mainly recommended for transverse thrusters.

Although shallow water and bank effects have an influence on ship behaviour and the full mission bridge simulator should be able to reproduce them, these factors are not considered in this research due to slow ship speed during arrival and departure manoeuvres (PIANC, 1980). Moreover, the expected tugboat scouring action during the alternative manoeuvres has not been included either for two reasons: First, the potential scour would occur in a different location: (i) during the arrival manoeuvre wash generated by the tug is directed outwards, perpendicular to the ship's heading, away from the quay wall to the outer basin, and (ii) during the departure manoeuvre, the tug is farther from the quay than the vessel, which is situated between the tug and the berth side, acting as a disturbing element for the free jet flow expansion. Second, the larger distance from the tug propeller to the wall and to the bottom (compared to that of the vessel) and its smaller dimensions indicate a low scouring action by applying the formulation (Eq. $(2-5))$ since they rely mainly on these parameters.

\section{CONCLUSIONS}

The Automatic Identification System (AIS) and the bridge simulator are useful tools to obtain parameters that otherwise are difficult to estimate when determining the potential scouring action of a ship. These parameters are used to calculate propeller velocities, which in turn are used to calculate maximum scour and identify potentially affected areas. It is found that greatest scour occurs near the back quay wall, when the stern propellers are working ahead, affecting harbour infrastructures, mainly during the departure manoeuvre. Weather conditions also have an influence on manoeuvres, especially arrival ones.

A qualitative method to reduce or even prevent scour using alternative manoeuvres for a studycase ship and a specific harbour area is presented. Results confirm a clear reduction of erosion depth. First, alternative manoeuvres without tug assistance are proposed. However, manoeuvres using a forward spring line have some limitations in adverse weather conditions 
(4Bf). Moreover, mooring lines for bigger ships are subjected to large stresses which may exceed a safe working load, thus putting the ship in danger and compromising the resistance of bollards against impact loads. Reduction of erosion and time is even more significant for alternative manoeuvres with tug assistance regardless weather conditions. Specifically, in departure manoeuvres the stern propellers do not work until the swing movement begins, away from the quay. However, this second option has an economic cost for ship owners which should be evaluated before proposing it as a solution for harbour infrastructures.

Therefore, AIS and the bridge simulator provide data that can be transformed into meaningful information for operational decision support to reduce the impact of erosion and sedimentation resulting from ship manoeuvres and used to assess port infrastructure and help port authorities and ship masters. Although the solution proposed in this contribution is for a specific port and ship, it can be used qualitatively in other scenarios. However, a quantitative data analysis should be carried out in order to find general assumptions for all ports, ship types and weather conditions.

\section{ACKNOWLEDGEMENTS}

We greatly acknowledge the contribution of Guillermo Pedrosa Eguílaz from Barcelona School of Nautical Studies (UPC).

\section{FINANCIAL SUPPORT}

This research has been supported by MINECO (Ministerio de Economía y Competitividad) and FEDER (Unión Europea- Fondo Europeo de Desarrollo Regional "Una Manera de Hacer Europa") from Spanish Government through project BIA2012-38676-C03-01 and TRA201570473-R.

\section{REFERENCES}

Aarsæther, K. G. and Moan, T. (2007) 'Combined Maneuvering Analysis, AIS and FullMission Simulation', TransNav: International Journal on Marine Navigation and Safety of Sea Transportation, 1, pp. 31-36.

Aarsæther, K. G. and Moan, T. (2009) 'Estimating Navigation Patterns from AIS', Journal of Navigation. Cambridge University Press, 62(04), p. 587. doi: 10.1017/S0373463309990129.

Bergh, H. and Magnussen, N. (1987) 'Propeller erosion and protection methods used in ferry terminals in the port of stockholm', Bulletin of the Permanent International Association of Navigation Congress (PIANC), 58.

Blaauw, H. G. and van de Kaa, E. J. (1978) 'Erosion of Bottom and Sloping Banks Caused by 
the Screw Race of Manoeuvring Ships, Publication N. 202', 7th International Harbour Congress, Antwerp, Belgium, 202.

Castells-Sanabra, M. et al. (2017) 'Tools for Evaluation Quay Toe Scouring Induced by Vessel Propellers in Harbour Basins During the Docking and Undocking Manoeuvring: Marine Navigation and Safety of Sea Transportation', in, pp. 61-66. doi: 10.1201/9781315099088-10.

Chait, S. (1987) 'Undermining of quaywalls at south african ports due to the use of bow thrusters and other prpeller units', Bulletin of the Permanent International Association of Navigation Congress (PIANC), 58, pp. 107-110.

Fuehrer, M., Pohl, H. and Römish, K. (1987) 'Propeller jet erosion and stability criteria for bottom protections of various constructions', Bulletin of the Permanent International Association of Navigation Congress (PIANC), 58.

Greidanus, H. et al. (2016) 'Completeness and Accuracy of a Wide-Area Maritime Situational Picture based on Automatic Ship Reporting Systems', Journal of Navigation. Cambridge University Press, 69(1), pp. 156-168. doi: 10.1017/S0373463315000582.

Hamill, G., Johnston, H. T. and Stewart, D. (1999) 'Propeller Wash Scour Near Quay Walls', Journal of Waterway, Port, Coastal and Ocean Engineering, 125(4), pp. 170-175.

Hamill, G., Ryan, D. and Johnston, H. T. (2009) 'Effect of rudder angle on propeller wash velocities at a seabed', Proceedings of the Institution of Civil Engineers-Maritime Engineering, 162(1), pp. 27-38.

Hawkswood, M. G., Lafeber, F. H. and Hawkswood, G. M. (2014) 'Berth scour protection for mordern vessels’, PIANC World Congress San Francisco USA 2014.

Hsu, W. K. K. (2015) 'Assessing the safety factors of ship berthing operations', Journal of Navigation, 68(3), pp. 576-588. doi: 10.1017/S0373463314000861.

Llull, T. et al. (2018) 'Hybrid tool to prevent ship propeller erosion', Proceedings of the ASME 2018 37th International Conference on Ocean, Offshore and Arctic Engineering (OMAE2018), pp. 1-10.

Llull, T. et al. (2020) 'Composite methodology to prevent ship propeller erosion', Ocean Engineering, 195, p. 106751. doi: 10.1016/j.oceaneng.2019.106751.

Mujal-Colilles, A et al. (2017) 'Erosion caused by propeller jets in a low energy harbour basin', Journal of Hydraulic Research. Taylor \& Francis, 55(1), pp. 121-128. doi: 10.1080/00221686.2016.1252801.

Mujal-Colilles, A. et al. (2017) 'Study of the Bed Velocity Induced by Twin Propellers', Journal of Waterway, Port, Coastal, and Ocean Engineering, 143(5), p. 04017013. doi: 10.1061/(ASCE)WW.1943-5460.0000382.

Mujal-Colilles, A., Llull, T., et al. (2018) 'Ship manoeuvring effects on propeller induced erosion', in International Conference on the Application of Physical Modelling to Port and Coastal Protection, pp. 1-7. Available at: http://hdl.handle.net/2117/118488.

Mujal-Colilles, A., Castells-Sanabra, M., et al. (2018) 'Stern Twin-Propeller Effects on Harbor', Water, 10(w). doi: 10.3390/w10111571.

Pallotta, G. et al. (2013) 'Vessel Pattern Knowledge Discovery from AIS Data: A Framework for Anomaly Detection and Route Prediction', Entropy. Multidisciplinary Digital Publishing 
Institute, 15(12), pp. 2218-2245. doi: 10.3390/e15062218.

PIANC (1980) Optimal Lay-Out and Dimensions for the Adjustment to Large Ships of Maritime Fairways in Shallow Seas, Seastraits and Maritime Waterways. Edited by I. commission for the reception of large Ships.

PIANC (2015) Guidelines for protecting berthing structures from scour caused by ships. Report $n^{\circ}$ 180. The World Association for Waterborne Transportation Infrastructure.

Römisch, K. and Hering, W. (2002) 'Input data of propeller induced velocities for dimensioning of bed protection near quay walls.', Bulletin of the Permanent International Association of Navigation Congresses.

Schokking, L. A., Janssen, P. C. and Verhagen, H. J. (2003) 'Bowthruster-induced damage', Bulletin of the Permanent International Association of Navigation Congress (PIANC), 114.

Silveira, P. A. M., Teixeira, A. P. and Soares, C. G. (2013) 'Use of AIS data to characterise marine traffic patterns and ship collision risk off the coast of Portugal', Journal of Navigation, 66(6), pp. 879-898. doi: 10.1017/S0373463313000519.

Symonds, A. et al. (2017) 'Predicting propeller wash and bed disturbance by recreational vessels at marinas', Bulletin of the Permanent International Association of Navigation Congres (PIANC).

Tan, R. İ. and Yüksel, Y. (2018) 'Seabed scour induced by a propeller jet', Ocean Engineering. Pergamon, 160, pp. 132-142. doi: 10.1016/J.OCEANENG.2018.04.076.

Tsinker, G. P. (1995) Marine Structures Engineering: Specialized Applications. Boston, MA: Springer US. doi: 10.1007/978-1-4615-2081-8. 